\title{
Novel PKLR missense mutation (A300P) causing pyruvate kinase deficiency in an Omani Kindred - PK deficiency masquerading as Congenital Dyserythropoietic Anemia.
}

Naglaa Fawaz ${ }^{1}$, Ismail Beshlawi ${ }^{1}$, Alauldeen Alqasim ${ }^{1}$, Mathew Zachariah ${ }^{1}$, Roberta

Russo $^{2}$, Immacolata Andolfo ${ }^{2}$, Antonella Gambale ${ }^{2}$, Anil Pathare ${ }^{3}$, and Achille Lolascon ${ }^{2}$

${ }^{1}$ Sultan Qaboos University Hospital

${ }^{2}$ CEINGE Biotecnologie Avanzate sc a rl

${ }^{3} \mathrm{SQUH}$

November 10, 2021

\begin{abstract}
A 15 year child is presented with transfusion dependent chronic anemia. The clinical and laboratory features suggested a chronic nonspherocytic hemolytic anemia (CNSHA) with bone marrow suggestive of congenital dyserythropoietic anemia (CDA). DNA studies revealed the underlying novel mutation in the PKLR gene responsible for pyruvate kinase deficiency.
\end{abstract}

Novel PKLR missense mutation (A300P) causing pyruvate kinase deficiency in an Omani Kindred - PK deficiency masquerading as Congenital Dyserythropoietic Anemia.

Naglaa Fawaz ${ }^{1,2}$, Ismail Beshlawi ${ }^{2}$, Alauldeen Alqasim ${ }^{2}$, Mathew Zachariah ${ }^{2}$, Roberta Russo ${ }^{3}$, Immacolata Andolfo ${ }^{3}$, Antonella Gambale ${ }^{3}$, Anil Pathare ${ }^{2}$, Achilles Lolascon ${ }^{3}$

Institutions:

${ }^{1}$ Department of Hematology, College of Medicine and Health Sciences, Sultan Qaboos University, Muscat, Oman.

${ }^{2}$ Department of Hematology, Sultan Qaboos University Hospital, Muscat, Oman.

${ }^{3}$ CEINGE Biotecnologie Avanzate, Napoli, Italy.

Abstract word count : 116

Text Word Count : 2583

No. of References : 19

The number of tables (1) and figures (2)

Running Title : Novel PKLR (A300P) mutation

Conflict of Interest : The authors declare no conflict of Interest

Consent: A written informed consent was obtained from the patient's guardian priopr to submission.

\#Address of Corresponding Author:

Dr. Naglaa Fawaz, MD, PhD. 
Associate Professor and Senior Consultant Haematopathologist,

Department of Haematology, College of Medicine \& Health Sciences,

Sultan Qaboos University, P. O. Box 35, Muscat 123,

Sultanate of Oman.

Phone: +96824144370

Fax: +96824144887

e-mail: gina_sa2002@yahoo.co.uk

\section{Abstract:}

We report herein a child with transfusion dependent chronic anemia, the cause of which was difficult to establish because of his transfusion dependency. The clinical and laboratory features suggested a chronic nonspherocytic hemolytic anemia (CNSHA) with bone marrow features suggestive of congenital dyserythropoietic anemia (CDA). DNA studies however revealed the underlying condition to be due to a novel mutation in the PKLR gene responsible for pyruvate kinase deficiency (PKD). Molecular investigations by a targeted next generation sequencing ( $\mathrm{t}-\mathrm{NGS}$ ) using a custom panel of 71 genes involved in the red blood cell (RBC) disorders revealed that the patient was homozygous for a novel missense mutation c.898G $>$ C, p.Ala300Pro, whereas both his parents were heterozygous for the same mutation.

\section{Introduction :}

Pyruvate kinase deficiency (PKD) is an inherited autosomal recessive metabolic disorder affecting the enzyme pyruvate kinase leading to the most common glycolytic defect producing a congenital non-spherocytic hemolytic anemia ${ }^{1}$. Pyruvate kinase (PK) converts phosphoenolpyruvate to pyruvate, augmenting the red blood cell (RBC) adenine triphosphate (ATP) production. Since the lifespan of an RBC is dependent on the amount of ATP production by glycolysis, PKD leads to lower ATP production and a reduced RBC survival. The RBCs in PKD are variably damaged with the youngest cells, at highest risk for destruction as they are the most dependent on ATP production by glycolysis, whereas, the older red cells are less affected ${ }^{2,3}$. Blockage in the splenic capillaries causes' damage to the affected RBCs, leading to an extravascular hemolysis as these RBCs are destroyed by the reticuloendothelial system both in the spleen as well as in the liver.

The gene encoding for PK (PKLR ) has been localized to the long arm of chromosome 1, with the cDNA coding for a 574 amino acids peptide ${ }^{4}$. More than 814 different mutations, mostly missense, have so far been described in association with PKD, with 529A and 1456 T being considered to be the most common mutations in Caucasians ${ }^{4,5}$. R510Q, which is the most frequently occurring mutation among Northern European population, has a dramatically decreased stability toward heat thus decreasing the enzyme level in the cell, accounting for the clinically observed PKD in patients who are homozygous for this mutation ${ }^{6}$.

The precise prevalence of PKD is unknown. Literature review have estimated the prevalence of carriers between 1-3\%, with a prevalence of PKD about 1 per 20,000 in the white population ${ }^{7,8}$. There is a high frequency of PKD among the Pennsylvania Amish community as a result of a founder effect ${ }^{9}$. Clinical features vary widely, ranging from a mildly symptomatic anemia to one that necessitates regular transfusions. Since the hemolytic process is chronic and begins since birth kernicterus is the commonest symptom, but the frequency of complications such as jaundice, gallstones, iron overload, severe anemia, thrombosis, and osteopenia is well documented ${ }^{10,11,12 .}$.

\section{Case-Report :}

AS, 15-year-male, presented at the age of 3 years with transfusion dependent anemia (12 transfusions/year) along with recently initiated oral iron chelation therapy, for iron overload. On examination, the patient has pallor, icterus, with a dry skin (diagnosed as Ichthyosis vulgaris). His vitals were normal, but per abdomen he had a $7 \mathrm{~cm}$ soft, non-tender splenomegaly with $4 \mathrm{cms}$ hepatomegaly below the costal margins. 
Investigations revealed a pretransfusion $\mathrm{Hb}$ of $8.7 \mathrm{~g} / \mathrm{dL}$, with dimorphic picture, mild polychromasia and numerous NRBC's (Table 1 ). Bone marrow examination showed erythroid hyperplasia, dyserythropoiesis with megaloblastic features, binuclear or multinuclear nucleated red cells and cytoplasmic bridging (Figs.1a \& 1b ). He was thus diagnosed as a case of congenital dyserythropoietic anemia (CDA) and investigated with several repeated bone marrow examinations with no different outcomes. Family history revealed that both the parents were consanguineous.

DNA studies were therefore performed by mutational screening for CDA1 causative genes (CDAN1 and C15ORF 41 ) by Sanger sequencing. Two rare variants namely c.256C $>$ T, p.Pro86Ser (rs543791953, MAF $<0.01$ ), inherited from the mother, and c. $773+107 \mathrm{G}>\mathrm{T}$, inherited from the father. Despite both variants being found in trans in the proband, subsequent analysis showed that the same genotype was identified in an unaffected brother of the proband, suggesting that this genotype was not the causative of the condition in the proband.

C15ORF41 mutational analysis showed the presence of several single nucleotide variants with unknown significance namely rs3743337, rs11073191, rs3784678, rs10220785 and rs6495863. However, no causative mutations in C15ORF41 gene were found.

Thus, DNA of the proband and both parents was further analyzed using a custom panel of 71 genes involved in the RBC disorders by means of targeted next generation sequencing (t-NGS) approach (RedPlex_rev1 ). RedPlex_rev1 panel includes causative and candidate genes involved in RBC membrane defects, RBC enzymatic defects, CDA and Diamond-Blackman anemia. The filtering of gene variants was carried out by means of a dedicated pipeline. This pipeline has considered variations in genes associated with the phenotype. Particularly, we included non-synonymous variants, as well as variants near splice sites or intronic, not annotated in public database or annotated with minor allele frequency (MAF) below 0.01 in the general population. The data obtained by t-NGS was confirmed on the DNA of the patient and his relatives, by amplification with primers specifically designed, followed by Sanger sequencing. It was demonstrated that the patient was homozygous for c.898G >C, p.Ala300Pro, whereas both his parents were heterozygous for the same mutation [ENST00000342741] (Fig. 2 ). The other unaffected siblings did not show homozygosity for this variant.

An EDTA blood sample was collected from the proband, 90 days after the last transfusion, subsequently the buffy coat was removed and the RBCs PK activity assay was performed by standard spectrophotometry method $^{13}$. The results compared with enzyme activity obtained from control samples with the same degree of reticulocytosis. Moreover, hexokinase (HK) activity was simultaneously estimated as another cell age dependent enzyme. Proband PK activity was $4.5 \mathrm{U} / \mathrm{g} \mathrm{Hb}$ (reference range, 5.6-14 U/g Hb) and $\mathrm{HK}$ activity was $1.5 \mathrm{U} / \mathrm{g} \mathrm{Hb}$ (reference range, 0.7-1.7 U/g Hb).

\section{Discussion:}

Our patient had a long standing history of chronic anemia, jaundice, and splenomegaly along with laboratory studies suggesting an underlying hemolytic anemia. The red cell morphology on the blood film was rather unremarkable and did not show any evidence of a membranopathy implying a diagnosis of chronic nonspherocytic hemolytic anemia (CNSHA). Biochemical studies showed increased LDH, total bilirubin with reduced serum haptoglobin but a negative coombs test. Moreover the patient needed periodic support with $\mathrm{RBC}$ transfusions. The bone morrow examination did not reveal any diagnostic pointers but showed dyserythropoiesis with subtle megaloblastic features, cytoplasmic bridging and nuclear irregularity was seen. Thus a working diagnosis of congenital dyserythropoietic anemia (CDA) was made and the patient was followed with blood transfusions 6-8 weeks with oral iron chelation therapy.

CDAs are a group of rare inherited RBC disorders characterized by mutations affecting RBC development in the bone marrow. Like PKD, CDA cause chronic hemolytic anemia, jaundice and splenomegaly, and, later in life, iron overload may develop. Moreover, similar to PKD, the RBC morphology may be normal or may show nonspecific abnormalities. But, unlike PKD, in the CDAs, the reticulocyte count is low and the bone marrow shows various abnormalities in developing RBC precursor cells. 
Clinically, inherited anemias i.e disorders due to hemoglobin mutations such as sickle cell disease, unstable hemoglobins or hemoglobin $\mathrm{H}$ disease, or RBC membrane defects such as hereditary spherocytosis or hereditary elliptocytosis could have resulted in the same clinical manifestations of our patients but relevant investigations ruled the above.

Lastly, acquired hemolysis or hemolytic anemia due to both intrinsic/intracorpuscular and extrinsic/extracorpuscular RBC defects would also explain the clinical features. Again like PKD, the age of presentation and severity of anemia are variable, the reticulocyte count is increased, and the peripheral blood smear may be unrevealing although occasionally spherocytes may be present. But unlike PKD, in acquired hemolysis and hemolytic anemia, a causative condition or medication can usually be identified from the medical history, medication list, or laboratory testing such as Coombs testing or EMA flow cytometry, which may reveal antibodies to RBCs or other defects such as absence of glycosylphosphatidylinositol (GPI)-anchored proteins.

PKD is the most frequent enzyme abnormality of the Embden-Meyerhof pathway causing hereditary CNSHA. PKD is an autosomal recessive disorder; with affected individuals being either homozygous for a single pathogenic mutation or compound heterozygous for two different pathogenic mutations affecting the function of the PK enzyme in RBCs and liver ${ }^{5,12}$ Individuals who are heterozygous for PK deficiency have intermediate enzyme levels and are not affected clinically. The PKLR gene is located on chromosome 1q21. ThePKLR gene encodes the $\mathrm{L}$ (liver) and $\mathrm{R}(\mathrm{RBC})$ isoenzymes. The $\mathrm{R}$ isoform, unique

to RBCs, is 33 amino acids larger than the $\mathrm{L}$ isoform, which is unique to hepatocytes. Expression in RBCs versus liver is due to differential use of tissue-specific promoters, which drive expression as well as tissuespecific exon usage (use of exon 1 but not exon 2 in RBCs and exon 2 but not exon 1 in liver) with over 250 pathogenic variants having been reported on the $P K L R$ gene $^{5,12,15}$.

In a study on 254 patients with molecularly confirmed PKD, perinatal complications including anemia that required transfusions, hyperbilirubinemia, hydrops, and prematurity were common ${ }^{16}$. Further, $93 \%$ newborns were treated with phototherapy and almost half were treated with exchange transfusions (46\%). Almost $3 / 4^{\text {th }}$ had to undergo splenectomy resulting in a significant reduction in the need for blood transfusion by $90 \%$. Almost half of the patients in this cohort had iron overload (48\%) and gallstones (45\%), but other complications such as aplastic crises, osteopenia/bone fragility, extra medullary hematopoiesis, post splenectomy sepsis, pulmonary hypertension, and leg ulcers were rare. Further, in those who had a splenectomy without simultaneous cholecystectomy, $48 \%$ later required a cholecystectomy. It is thus recommended that diagnostic testing for PKD should be considered in patients with apparent congenital hemolytic anemia and close monitoring for iron overload, gallstones, and other complications is needed regardless of baseline hemoglobin ${ }^{16}$.

Causative mutations in homozygous state or compound heterozygous state in this gene have been already described as causative of PKD. Further, it has been recently demonstrated that several patients presenting with clinical data and morphological features of the bone marrow mostly resembling those of both CDAI and $\mathrm{CDAII}^{17}$. The variant identified in the proband is neither currently annotated in public databases nor described as causative mutation of $\mathrm{PKD}^{5}$. But following the guidelines by ACMG/AMP 2015 for the clinical interpretation of genetic variants, this novel variant is classified as pathogenic ${ }^{18}$. Whereas the complementary PK activity assay for the proband, showed lower level compared to the matched control, meanwhile the HK activity results was within normal, diagnosis is highly in favor of pyruvate kinase deficiency ${ }^{19}$. The findings are also harmonize with the molecular heterogeneity of pyruvate kinase deficiency ${ }^{5}$.

\section{References :}

1. Tanaka KR, Valentine WN, Miwa S. Pyruvate kinase (PK) deficiency hereditary nonspherocytic hemolytic anemia. Blood. 1962; 19: 267-295.

2. Nathan DG, Oski FA, Miller DR, Gardner FH. Life-span and organ sequestration of the red cells in pyruvate kinase deficiency. N Engl J Med 1968; 278: 73-81. 
3. Mentzer WC,Jr, Baehner, RL, Schmidt-Schonbein H, Robinson SH, Nathan DG. Selective reticulocyte destruction in erythrocyte pyruvate kinase deficiency. J Clin Invest 1971; 50:688-699.

4. Zanella A, Bianchi P. Red cell pyruvate kinase deficiency: from genetics to clinical manifestations. Baillieres Best Pract Res Clin Haematol. 2000 Mar; 13(1):57-81.

5. Paola Bianchi and Elisa Fermo. Molecular heterogeneity of pyruvate kinase deficiency, Haematologica 2020; 105(9):2218-2228.

6. Wang C, Chiarelli LR, Bianchi P, Abraham DJ, Galizzi A, Mattevi A, et al. Human erythrocyte pyruvate kinase: characterization of the recombinant enzyme and a mutant form (R510Q) causing nonspherocytic hemolytic anemia. Blood. 2001 Nov 15; 98(10):3113-20.

7. Beutler E, Gelbart T. Estimating the prevalence of pyruvate kinase deficiency from the gene frequency in the general white population. Blood. 2000; 95(11):3585-3588.

8. Carey PJ, Chandler J, Hendrick A, Reid MM, Saunders PW, Tinegate H, et al.; Northern Region Haematologists Group. Prevalence of pyruvate kinase deficiency in northern European population in the north of England. Blood. 2000; 96(12):4005-4006.

9. Rider NL, Strauss KA, Brown K, Finkenstedt A, Puffenberger EG, Hendrickson CL, et al. Erythrocyte pyruvate kinase deficiency in an old-order Amish cohort: longitudinal risk and disease management. Am J Hematol. 2011; 86(10):827-834.

10. Pissard S, Max-Audit I, Skopinski L, Vasson A, Vivien P, Bimet C, et al. Pyruvate kinase deficiency in France: a 3-year study reveals 27 new mutations. Br J Haematol. 2006; 133(6):683-689.

11. Lenzner C, Nurnberg P, Jacobasch G, Gerth C, Thiele BJ. Molecular analysis of 29 pyruvate kinasedeficient patients from central Europe with hereditary hemolytic anemia. Blood.1997; 89(5):1793-1799.

12. Zanella A, Fermo E, Bianchi P, Chiarelli LR, Valentini G. Pyruvate kinase deficiency: the genotypephenotype association. Blood Rev. 2007; 21(4):217-231.

13. Beutler E. Red Cell Metabolism: A Manual of Biochemical Methods. New

York: Grune \& Stratton Inc.; 1984.

14. Gregg XT, Prchal JT. Red blood cell enzymopathies. In: Hematology: Basic Principles and Practice, 7th ed, Hoffman R, Benz E, Silberstein LE, et al (Eds), Elsevier, Philadelphia 2017.

15. Canu G, De Bonis M, Minucci A, Capoluongo E. Red blood cell PK deficiency: An update of PK-LR gene mutation database. Blood Cells Mol Dis 2016; 57:100.

16. Grace RF, Bianchi P, van Beers EJ, Eber SW, Glader B, Yaish HM, et al. Clinical spectrum of pyruvate kinase deficiency: data from the Pyruvate Kinase Deficiency Natural History Study. Blood. 2018 May 17; 131(20):2183-2192.

17. Russo R, Andolfo I, Manna F, Gambale A, Marra R, Rosato BE, et al. Multi-gene panel testing improves diagnosis and management of patients with hereditary anemias. Am J Hematol. 2018 May; 93(5):672-682. doi: $10.1002 /$ ajh.25058

18. Grace RF, Zanella A, Neufeld EJ, Morton DH, Eber S, Yaish H, et al. Erythrocyte pyruvate kinase deficiency: 2015 status report. Am J Hematol. 2015 Sep;90(9):825-30. doi: 10.1002/ajh.24088

19. Bianchi P, Fermo E, Glader B, Kanno H, Agarwal A, Barcellini W et al. Addressing the diagnostic gaps in pyruvate kinase deficiency: Consensus recommendations on the diagnosis of pyruvate kinase deficiency. Am J Hematol. 2019 Jan;94(1):149-161.

\section{Acknowledgements :}


We sincerely thank the Hospital Director for the use of clinical material. We also sincerely thank the Unita Operativa Complessa Biologia Molecolare Clinica, D.A.I di Medicina di Laboratoria \& CEINGE - Biotecnologie Avanzate, Centro di riferimento Regione Campania per la, Biologia Molecolare Clinica, laDiagnostica di Malattie Congenite del Metsbolismo e delle Malattie Rare, Napoli, Italy and specifically Prof. Achille Iolascon, Functional Area Manager, Medical Genetics, Napoli, Italy for processing the DNA molecular studies to its fruition.

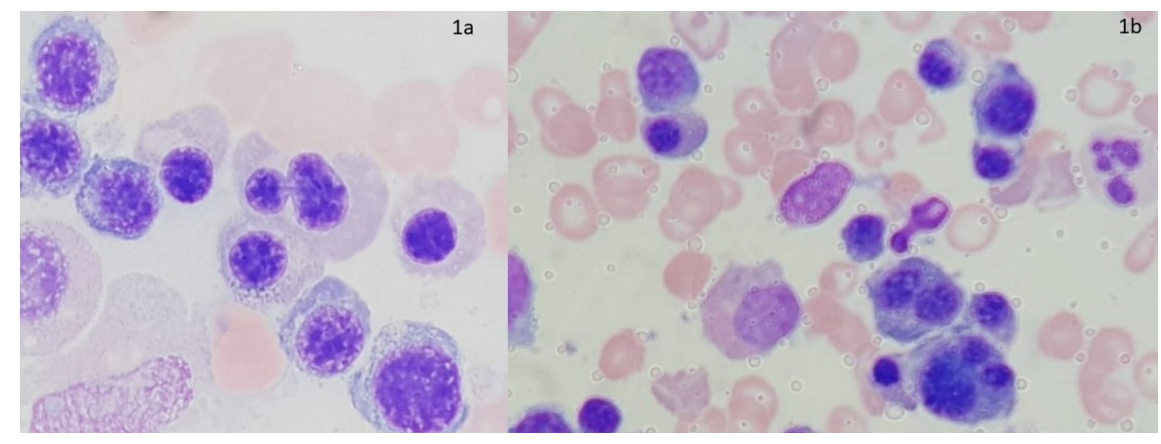

Figure 1: Bone Marrow showing megaloblastic features, binuclear or multinuclear nucleated red cells and cytoplasmic bridging

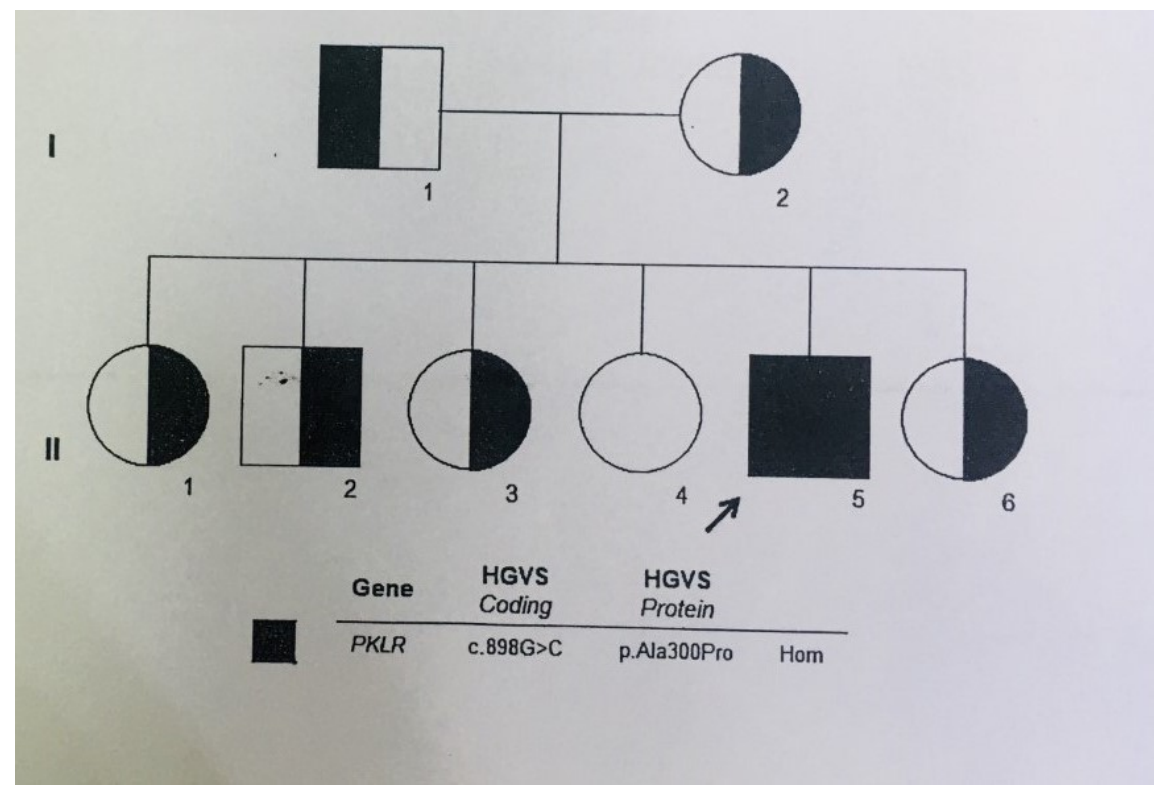

Figure 2: Pedigree analysis of the inheritance pattern of the PKD kindred

Table 1: Hematological and Biochemical parameters in the PKD kindred

\begin{tabular}{|c|c|c|c|c|c|c|c|}
\hline & $\begin{array}{l}\text { Initials, } \\
\text { Genotype } \\
\text { c.898G }>\text { C; } \\
\text { p.Ala300Pro }\end{array}$ & Relation & $\begin{array}{l}\text { Sex, } \\
\text { Age(years) }\end{array}$ & $\begin{array}{l}\mathrm{Hb}(\mathrm{g} / \mathrm{dL}) \\
\mathrm{RR} \\
11.5-14.5\end{array}$ & $\begin{array}{l}\text { Retic RR } \\
0.2-2(\%)\end{array}$ & $\begin{array}{l}\text { Total } \\
\text { Bilirubin } \\
\text { (umol/L) } \\
\text { RR 0-17 }\end{array}$ & $\begin{array}{l}\text { Haptoglobin } \\
\text { RR } \\
0.36-1.95 \\
(\mathrm{~g} / \mathrm{L})\end{array}$ \\
\hline I.1 & $\begin{array}{l}\mathrm{SH}, \\
\text { Heterozygous }\end{array}$ & Father & $\mathrm{M}, 45$ & 13.3 & 1.6 & 4 & 1.2 \\
\hline
\end{tabular}




\begin{tabular}{|c|c|c|c|c|c|c|c|}
\hline & $\begin{array}{l}\text { Initials, } \\
\text { Genotype } \\
\text { c.898G }>\text { C; } \\
\text { p.Ala300Pro }\end{array}$ & Relation & $\begin{array}{l}\text { Sex, } \\
\text { Age(years) }\end{array}$ & $\begin{array}{l}\mathrm{Hb}(\mathrm{g} / \mathrm{dL}) \\
\mathrm{RR} \\
11.5-14.5\end{array}$ & $\begin{array}{l}\text { Retic RR } \\
0.2-2(\%)\end{array}$ & $\begin{array}{l}\text { Total } \\
\text { Bilirubin } \\
\text { (umol/L) } \\
\text { RR 0-17 }\end{array}$ & $\begin{array}{l}\text { Haptoglobin } \\
\text { RR } \\
0.36-1.95 \\
(\mathrm{~g} / \mathrm{L})\end{array}$ \\
\hline $\mathrm{I} .2$ & $\begin{array}{l}\text { FA, } \\
\text { Heterozygous }\end{array}$ & Mother & $\mathrm{F}, 38$ & 12.6 & 1.8 & 3 & 1.3 \\
\hline II.1 & $\begin{array}{l}\text { AS, } \\
\text { Heterozygous }\end{array}$ & Sister & $\mathrm{F}, 21$ & 11.6 & 1.6 & 5 & 0.9 \\
\hline II. 2 & $\begin{array}{l}\text { OS, } \\
\text { Heterozygous }\end{array}$ & Brother & M,19 & 12.3 & 1.7 & 2 & 1.1 \\
\hline II. 3 & $\begin{array}{l}\text { MS, } \\
\text { Heterozygous }\end{array}$ & Sister & $\mathrm{F}, 17$ & 11.8 & 0.8 & 3 & 1.2 \\
\hline II.4 & $\begin{array}{l}\text { SS, } \\
\text { Normal }\end{array}$ & Sister & $\mathrm{F}, 16$ & 11.7 & 1.1 & 4 & 1.1 \\
\hline II. 5 & $\begin{array}{l}\text { AS, } \\
\text { Homozygous }\end{array}$ & Proband & $\mathrm{M}, 15$ & 8.7 & 4.7 & $18-45$ & $<0.06$ \\
\hline II. 6 & $\begin{array}{l}\text { SS, } \\
\text { Heterozygous }\end{array}$ & Sister & $\mathrm{S}, 12$ & 12.2 & 1.3 & 2 & 1.2 \\
\hline
\end{tabular}

